\title{
Editorial
}

\section{What have you all been reading?}

Elaine Hall

Northumbria University, UK

\section{Elaine.Hall@northumbria.ac.uk}

I would like to start this Editorial with a couple of apologies. The first is the lateness of this edition, planned for February and delayed by me taking ages to work out how to embed video. The second is that I misjudged you, dear clinical scholars. I thought that you went straight to the 'meat' and didn't pause to read these editorial amusebouches. However, while studying the download reports for the journal I realised that some of you do and from now on, I will make extra effort to include something nutritious.

The IJCLE has been online since 2014 and in that time, more than 20,000 papers have been downloaded. A quick analysis of the data gives some interesting messages: the ten 'digital age' issues have an impressive performance in bringing clinical scholarship to a wider audience, over 10,000 downloads and an average of over 300 per paper, which is on a par with established journals like the Law Teacher. The Special Issue on Assessment attracted the most attention as a collection of papers - so please send your ideas for special issues to me!- and currently the most popular paper is Paul McKeown's Law Students' attitudes towards Pro Bono. This seems likely to change (sorry Paul!) not only as new papers are published but as the visibility and use of 
papers in the archive continues to build. As the numerate amongst you will already have noticed, half of all downloads are from the 'pre-digital' editions, despite many of these being available via HeinOnline. This data cheers me enormously for at least two reasons:

1. We can demonstrate the impact of clinical scholarship and the vitality of the audience for the IJCLE: it is worth sending your papers here. They will be read, challenged and contribute to the clinical discourse.

2. Clinical scholars are heeding the messages from recent systematic reviews ${ }^{1}$ and heading back into our history to elicit the lessons buried there. We are becoming more critical and sophisticated in using our traditions, as well as engaging beyond our disciplinary boundaries.

To add a degree of randomness or serendipity to this process, I'm instituting an idea from my favourite food blog, smitten kitchen - the Archive Dive. Therefore from this issue we direct your attention back to Volume 11 where you'll find papers on multicultural (Ada Okoye Ordor) and indigenous (Anna Cody and Sue Green) perspectives, an overview of CLE within Law (Margaret Barry) and a paper on ethics (Kevin Kerrigan). These are still hot topics and I'm delighted to say that you can catch some of these clinicians at the IJCLE, ENCLE and CLEO conference in July this year more details below.

\footnotetext{
${ }^{1}$ Mkwebu, T IJCLE 22, 3, 2015; Dunn IJCLE 24, forthcoming.
} 
Meanwhile, in this edition, we have an important paper on research methods to investigate the impact of clinic from Lisa Bliss, Sylvia Caley and Leslie Wolf, crystallising the learning from their intensive programme of investigation at Georgia State University. Many of you who have been able to take part in their interactive seminars at GAJE/IJCLE at Anadolu University in Eskisehir, Turkey in 2015 and IJCLE/ACCLE at the University of Toronto in 2016 have been asking for more and we are delighted to be able to provide this paper.

We return to the debate around assessment and the value of clinical education for students with the first of our practice reports from Patrick Koroma and Nicola Antoniou which looks at the perceived benefits of CLE. Do our students value their clinical experience and can they parlay that into employment? If these things are not simple and linear, is that in part due to what we as academics appear to value, in part due to the values of the profession and in part due to issues of translation?

In the second practice report, we bring you the artefacts from a very exciting day conference held at London South Bank University on the $11^{\text {th }}$ November 2016 . The report contains the material shared by the participants before the event and videos of the clinicians describing their work and answering questions - click on the pictures on the last page to access the videos, you may need to right click then select 'Open hyperlink'. 
And finally, the inevitable reminder that three organisations are coming together for the 2017 conference. Registration is open and we look forward to welcoming you to Newcastle!

\section{IJCLE - ENCLE - CLEO}

The International Journal of Clinical Legal Education in association with the

European Network for Clinical Legal Education

and the

United Kingdom Clinical Legal Education Organisation

\section{CONFERENCE 3-5 JULY 2017}

at the University of Northumbria, Newcastle upon Tyne, UK

"Bringing It All Together: Clinical Legal Educators in the 21st Century University"

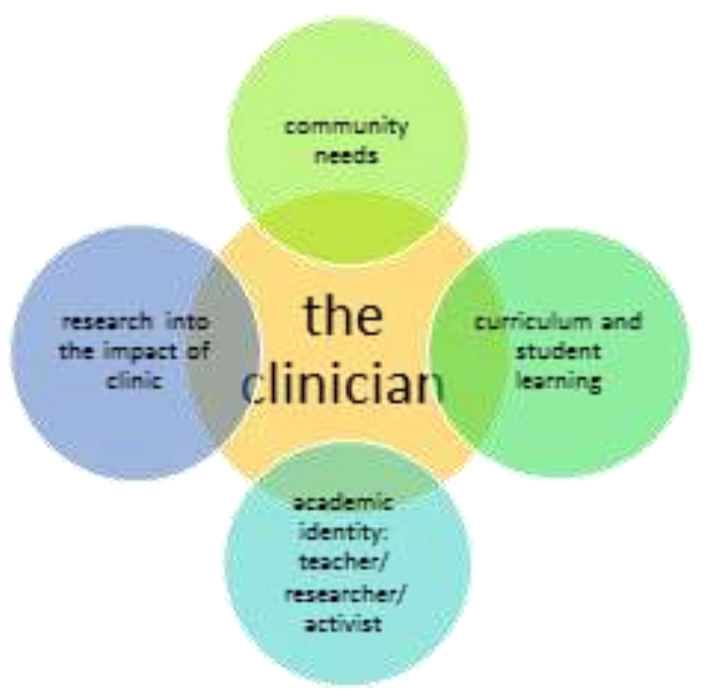


Clinicians wear many hats: teacher, group facilitator, project manager, lawyer, researcher, mentor, activist, administrator, supervisor, academic, fund raiser, practice manager, collaborator, role model, counsellor...

This year's conference continues our exploration of the key, often overlapping, issues arising for clinical legal education in the $21^{\text {st }}$ century from the clinician's perspective; juggling sometimes competing priorities and often making difficult choices. These will be explored by our Keynote panel: Lisa Bliss, Mary Anne Noone, Shuvro Sarker and Veronika Tomoskova.

Our welcome keynote comes from Professor Kevin Kerrigan:

"If I ruled the world - can clinic be required in every discipline?"

"Such happiness as life is capable of comes from the full participation of all our powers in the endeavor to wrest from each changing situation of experience its own full and unique meaning."

John Dewey, the granddaddy of experiential learning, was not referring here to the discipline of law. His was a broad pedagogic philosophy that was not discipline-specific.

It is well known (although not always acknowledged) that clinical education was not invented by lawyers and although clinical legal education has developed into a distinctive and highly successful strand of experiential learning, it remains a methodology that is at least potentially applicable right across the academy. Where university education is closely linked to professional training or development, there is often a motivation to deploy a clinical approach but it is much more challenging to envisage a clinical approach right across the subject spectrum. I am unaware of any institution that has attempted to deliver a comprehensive suite of academic programmes via meaningful clinical engagement.

During the selection process for my current role I pitched the idea that we could develop a live client clinical approach right across the undergraduate curriculum. The good news was I got the job. The bad news was that they took my idea seriously.

So, can clinic be required in every discipline? Even if it can, does it make educational sense? Maths clinic anyone? 